\title{
Reduced Harmonics Generated and Reactive Volt-Ampere absorption of HVDC Converter Using By-Pass Switch
}

\author{
HUSSEIN D. AL-MAJALI \\ BILAL H. AL-MAJALI \\ Department of Electrical Enging Department of Electrical Enging \\ Faculty of Engineering \\ Mu'tah University \\ Al-Karak, JORDAN \\ Faculty of Engineering \\ Al-Balqa Applied University \\ Al-Salt, JORDAN
}

\author{
ZIYAD S. ALMAJALI \\ Department of Electrical Enging \\ Faculty of Engineering \\ Mu'tah University \\ Al-Karak, JORDAN
}

\begin{abstract}
Control of a conventional converter station which uses a three-phase controlled bridge for converting $\mathrm{AC}$ to $\mathrm{DC}$ and vice-versa is achieved by fast-acting control of the valve firing angles. Tap-changers which are fitted on the converter transformer provide a near constant $\mathrm{AC}$ voltage input to the bridge to correct relatively slow changes of $\mathrm{AC}$ voltage. This paper describe a modification of the conventional bridge circuit, using by-pass valves connected to tapping points on the secondary winding of the transformer. This scheme permits a wide range of voltage control with a reduction in both the harmonic generation and the reactive volt- ampere absorption, and possibly eliminates the need for an on-load tap-changer on the converter transformer. Experimental results on a laboratory model compare well with the predicted values.
\end{abstract}

Key words: Modified converter; Harmonics Analysis; Reactive Power

Received: November 25, 2019. Revised: May 2, 2020. Accepted: May 18, 2020. Published: June 2, 2020.

\section{Introduction}

The world-wide demand for electrical energy over the past years indicates a high percentage rate of growth per year. The basic function of a modern electric power system is to supply the system load as economically as possible and with a reasonable assurance of continuity and quality. A power system should be designed and planned so that the probability of failing to perform its basic function is at an acceptable level. However, there are certain applications where direct current transmission offers distinct economic and/or technical advantages [1]. These include longdistance overhead transmission lines, relatively short-distance submarine power transmission lines, underground cable connections, and asynchronous ties between two systems of different frequencies.

Phase-controlled thyristor converters have been widely used in AC-DC conversion applications were output voltage control is required. The static power converters are non-linear in nature, and consequently they generate harmonics into the supply. The generations of harmonics as well as several methods for harmonic reduction and power factor improvement are well explained in the existing literature [2-10].

An HVDC converter has normally a basic control system that controls the direct current in the rectifier and the extinction angle in the inverter. The basic control system is, however, the heart of the system, and to high degree it determines the operation properties of the whole HVDC plant. Although, there are a number of control schemes for AC-DC conversion to improve the power factor and reduce harmonics, the angle controlled scheme is still widely used in practical application. Several methods of control and transients have been reported in the literature [11-17].

In this paper the conventional bridge is modified in such a way that it has additional thyristors which form by-pass thyristors on each phase. In this configuration, fast and continuous control of the DC voltages is possible, and the need for an on-load tap-changer may be removed. The direct voltage can be controlled by controlling the firing angles of the by-pass thyristors. Harmonic generation into the $\mathrm{AC}$ system and the converter reactive volt-ampere absorption may be reduced, but more switching devices and therefore control circuit are required compared with the conventional converter requirements.

\section{Control of conventional converter}

An important characteristic of HVDC transmission is the fast and accurate control of power flow. In the control of a DC link, the direct 
voltage is kept as high as possible and the transmitted power is controlled by varying the current. The typical equivalent converter circuit for a HVDC system is shown in Fig.1, the voltage and current waveforms are shown in Fig. 2 and Fig.3. The DC current $\left(I_{d}\right)$ is given by:

$$
I_{d}=\frac{V_{o r} \cos \alpha-V_{o i} \cos \beta}{R_{r}+R_{l}+R_{i}}
$$

where $R_{l}$ is the DC line resistance.

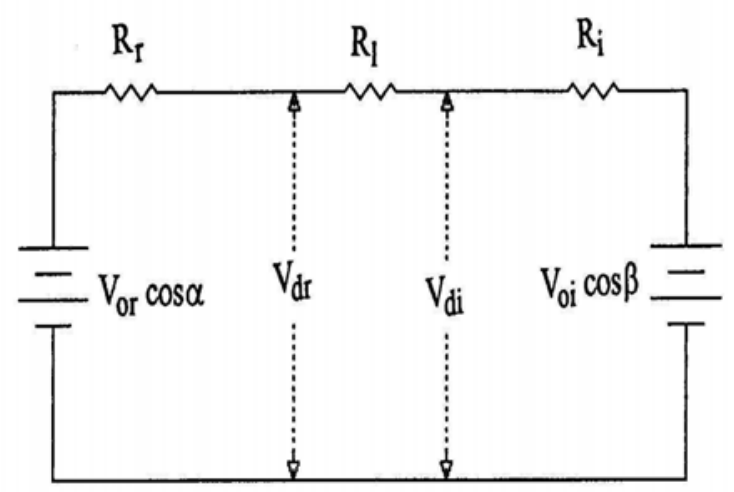

Fig.1: DC transmission system equivalent circuit

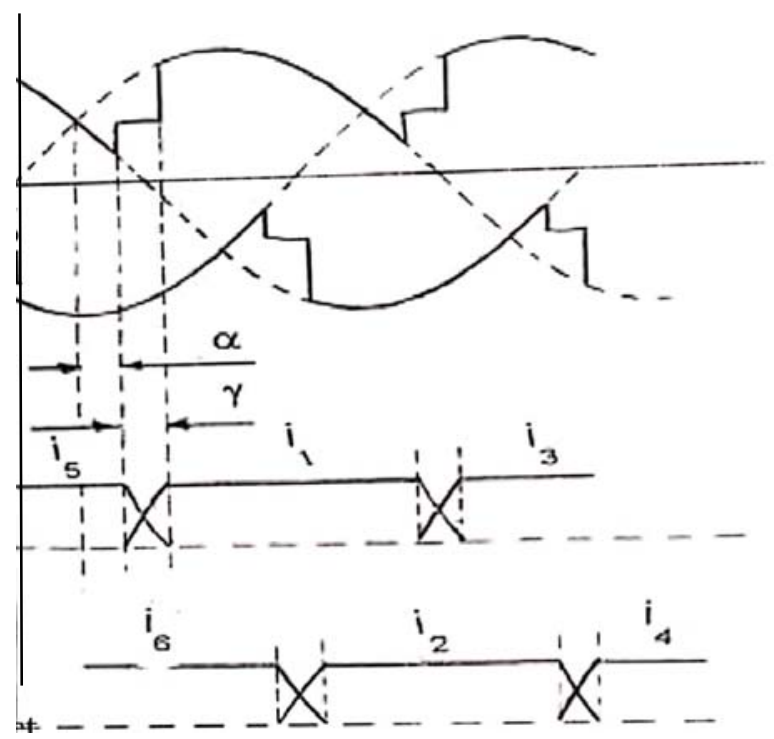

Fig.2: Typical voltage and current waveforms for conventional converter (Rectifier)

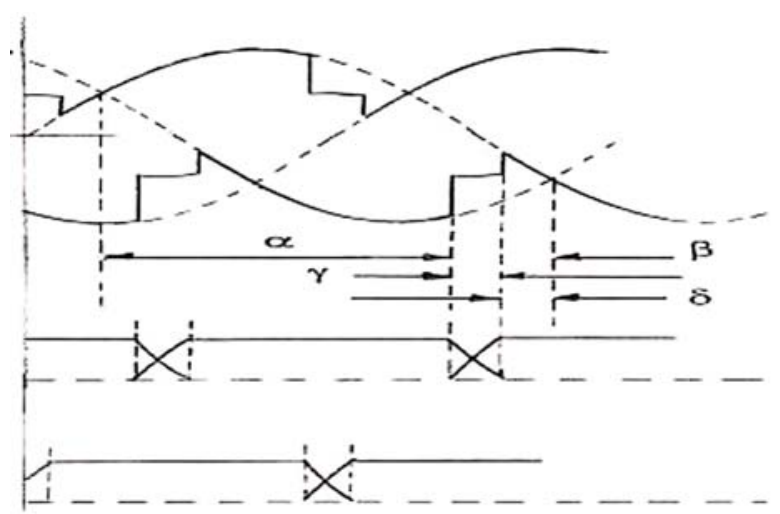

Fig.3: Typical voltage and current waveforms for conventional converter(Inverter)

\subsection{Fast acting control}

In HVDC, any small changes in the direct voltage difference between terminals will give a high change in direct current due to a small value of line resistance. The control must change the ratio between direct voltage and $\mathrm{AC}$ voltage by varying the firing angle $\alpha$ or by on load tap-changer control, which varies the alternating voltage on the valve side. Fig.4 shows the complete control characteristics of a converter from full rectification to full inversion $\left(V_{d}\right.$ against $\left.I_{d}\right)$. The rectifier normally operates on constant current control (C.C), and the inverter on minimum extinction angle control (C.E.A).

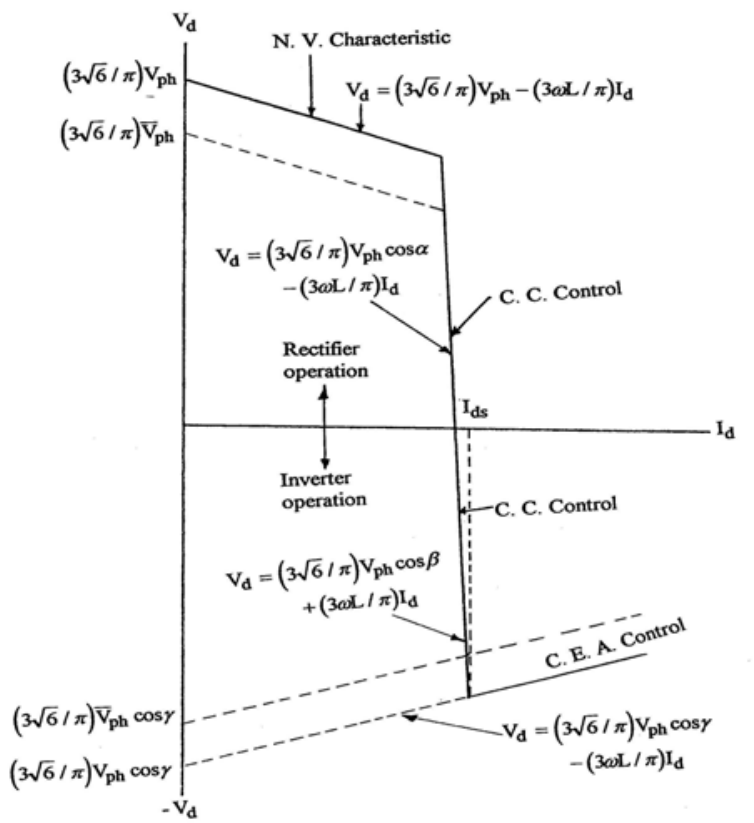

Fig.4: General characteristics of $V_{d}$ against $I_{d}$ for the converter [13] 
At delay angles $\alpha=0$, the DC voltage $V_{d}$ is given by:

$V_{d}=\frac{3 \sqrt{6}}{\pi} V_{p h}-\frac{3 \omega L}{\pi} I_{d}$

Therefore, the level of the natural voltage characteristic can be adjusted by the transformer onload tap-changer. If $V_{p h}$ reduces to a smaller value, say $\bar{V}_{p h}$, then the C.E.A and the natural voltage characteristic will drop accordingly, as shown by the dotted lines in Fig.4.

At delay angles larger than $\alpha=0$, the converter exercises constant current control to maintain a current reference $\left(I_{d s}\right)$, which has a practically vertical characteristic. In this region the DC voltage is given by:

$V_{d}=\frac{3 \sqrt{6}}{\pi} V_{p h} \cos \alpha-\frac{3 \omega L}{\pi} I_{d}$

and is limited by the need to maintain a certain minimum extinction angle required for safe commutation.

\subsection{Tap-changer control}

The power factor $\cos \phi_{1}$ for the fundamental component is given as:

$\cos \phi_{1}=(1 / 2)(\cos \alpha+\cos (\alpha+\gamma))$

So, the power factor is affected by the firing angle $\alpha$ for rectifier operation. It is clear that when $\alpha$ increases the power factor will decrease; therefore the reactive volt-ampere consumed by the rectifier will be increased for the same AC current and voltage. To minimize the reactive volt-ampere, the firing angle must be kept at a minimum limit [1821]. The tap-changer on the rectifier side is controlled to keep the delay angle $(\alpha)$, and therefore the amount of voltage in hand ( CD on Fig.4) within prescribed limits. This also keeps the reactive voltampere at its minimum value. When the working point falls, the rectifier tap-changer will reduce the AC voltage to keep the working point near to the highest level and the power factor is increased. Also, the reactive volt-ampere on the inverter side is minimized at $\delta=\delta 0$ limit; this is achieved by providing a tap-changer on the inverter transformer to keep the direct voltage within any desired limits. So, the aim of the tap-changer is to allow the DC line voltage to be maintained sensibly constant for slow changes of AC voltage variation, providing operation at minimum VAR absorption at a safe extinction angle [16].

\section{Basic operation of the modified bridge converter}

The basic modified bridge circuit is shown in Fig.5, has additional thyristors which form a ' bypass' thyristor. There are two modes of operation possible with the modified bridge
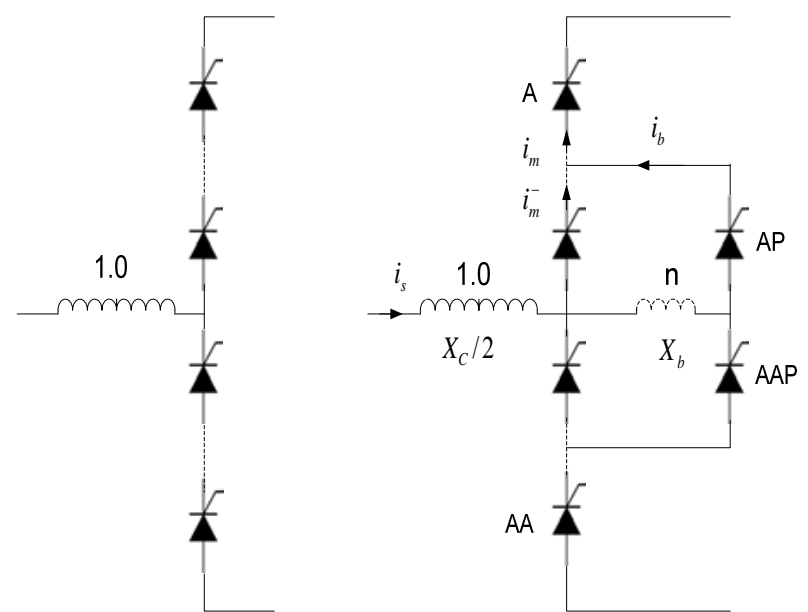

Fig.5: One phase of Modified Converter [14]

a) Normal operation: the main valve firing angle $\alpha$ is kept near zero in the rectifier mode of operation, and the DC voltage is controlled by variation of the by-pass valve firing angle ( $\alpha_{b}$ ). When the bridge is operating as an inverter, the by-pass valves are fired before the main valve because commutation occurs from higher ( more negative) voltage to lower ( less negative) voltage. The DC voltage can be controlled by variation of the angle of advance $\left(\beta_{b}\right)$ by providing a safe extinction angle. The inverter is operated at its safe minimum extinction angle $(\delta)$. In both operating modes, the firing pulses are arranged so that when they are applied to the by-pass valves, the sections of main valves in parallel with the by-pass valves have no gate signals and vice-versa.

b) Abnormal operation ( conventional converter): in this case the main and by-pass valves are fired together, and therefore the bridge reverts to the conventional control mode. 


\subsection{Converter performance analysis}

The method of control in the rectifier mode is to keep the main thyristor firing angle $\alpha$ at a small value, and the $\mathrm{DC}$ voltage is controlled by variation of by-pass thyristor firing angle $\alpha_{b}$. Both voltage and current waveforms are shown in Fig.6, Fig.7 and Fig.8. There are two commutation processes are considered, current transfer between the main thyristors and current transfer between the bypass thyristors $\mathrm{S} 2$ and the section of main thyristor designated S1. The reactance of the main-thyristor circuit during commutation is the conventional commutation reactance $X_{c}$ with additional reactance $X_{b}$ due to the tapped section turns. After firing a by-pass thyristor, the rate of increase in current through the thyristor is controlled by the section voltage $n V_{p h}$ and the reactance $X_{b}$. Natural commutation is delayed by an angle $\alpha_{0}$ owing to the difference between the main and by-pass thyristor voltages. The following expressions have been used in the derivation of the DC voltage:

$V_{A}=\sqrt{2} V_{p h} \sin \omega t$

$\bar{V}_{A}=\sqrt{2}(1+n) V_{p h} \sin \omega t$

$V_{B}=\sqrt{2} V_{p h} \sin (\omega t-120)$

$\bar{V}_{B}=\sqrt{2}(1+n) V_{p h} \sin (\omega t-120)$

$V_{C}=\sqrt{2} V_{p h} \sin (\omega t+120)$

$\bar{V}_{C}=\sqrt{2}(1+n) V_{p h} \sin (\omega t+120)$

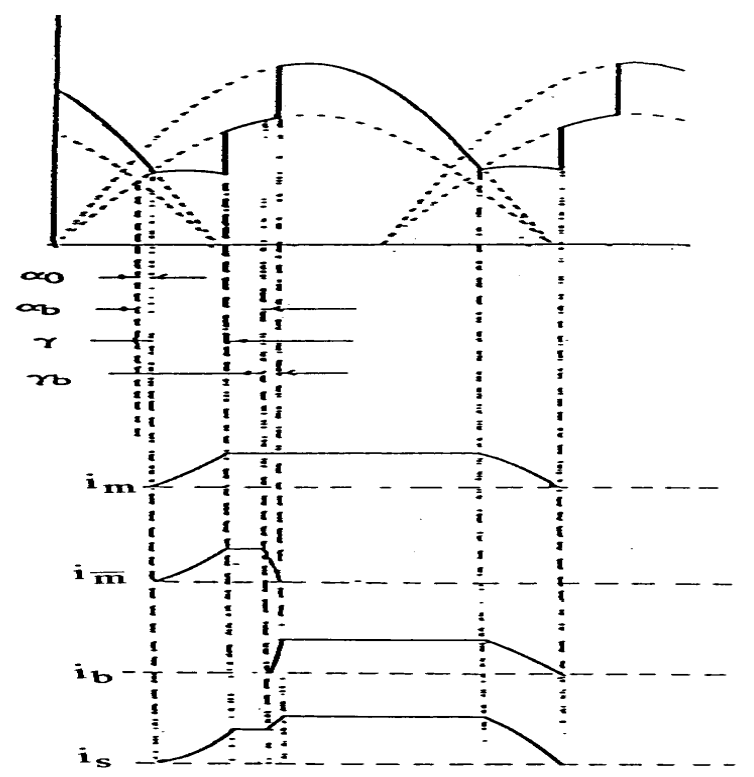

Fig.6: Typical voltage and current waveforms for Modified converter (Rectifier) [14]

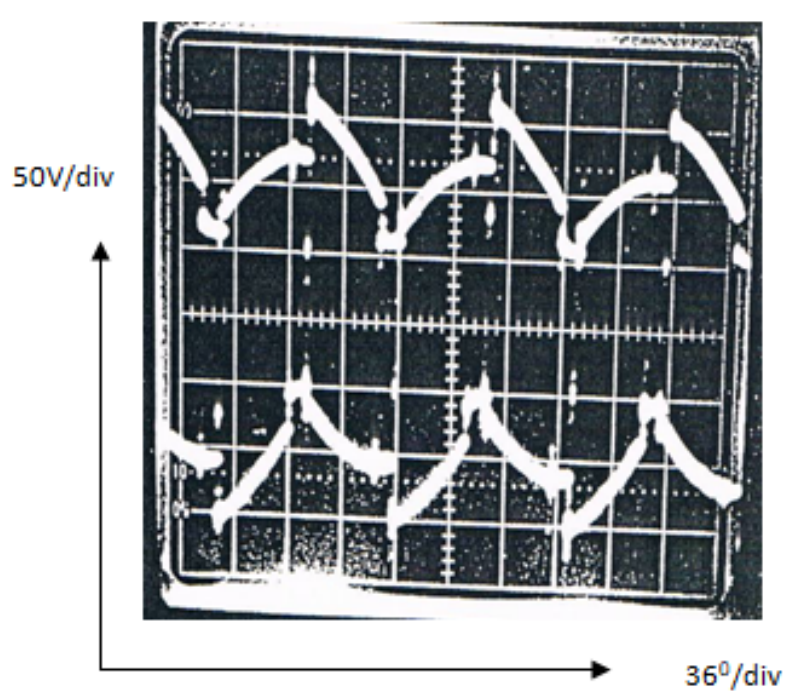

Fig.7: Typical Oscillograms of voltage for Modified converter ( Rectifier) [14]

\subsection{Rectifier mode of operation}

a) For $0 \leq \alpha_{b} \prec \alpha_{0}$, the limits of the output voltage for different parts given as:

$$
V_{d}=\left.\frac{3}{\pi} \frac{\overline{V_{C}}+\overline{V_{A}}}{2}\right|_{(\pi / 6)+\alpha_{b}} ^{(\pi / 6)+\alpha_{b}+\gamma}
$$




$$
V_{d}=\left.\frac{3}{\pi} \overline{V_{A}}\right|_{(\pi / 6)+\alpha_{b}+\gamma} ^{(5 \pi / 6)+\alpha_{b}}
$$

Therefore

$V_{d}=(n+1) V_{0}\left[\cos \alpha_{b}+\cos \left(\alpha_{b}+\gamma\right)\right] / \sqrt{2}$

Where

$$
V_{0}=\frac{3 \sqrt{6} V_{p h}}{\pi}
$$

Mean DC voltage on no-load and no by-pass valve in circuit.

$$
\gamma=\cos ^{-1}\left[\cos \alpha_{b}-\frac{\left(X_{0}+2 X_{b}\right) I_{d}}{V_{p h} \sqrt{6(n+1)}}\right]-\alpha_{b}
$$

b) For $\alpha_{0} \leq \alpha_{b} \prec\left(\gamma+\alpha_{0}-\gamma_{b}\right)$, limits of output voltage for different part are given as:

$$
\begin{gathered}
V_{d}=\left.\frac{3}{\pi} \frac{\overline{V_{C}}+V_{A}}{2}\right|_{(\pi / 6)+\alpha_{0}} ^{(\pi / 6)+\alpha_{b}+\gamma_{b}} \\
V_{d}=\left.\frac{3}{\pi} \frac{\overline{V_{C}}+\bar{V}_{A}}{2}\right|_{(\pi / 6)+\alpha_{b}+\gamma_{b}} ^{(\pi / 6)+\alpha_{0}} \\
V_{d}=\left.\frac{3}{\pi} \overline{V_{A}}\right|_{(\pi / 6)+\alpha_{b}+\gamma} ^{(5 \pi / 6)+\alpha_{0}}
\end{gathered}
$$

Therefore

$$
V_{d}=\frac{V_{0}}{\sqrt{3}}\left[\begin{array}{l}
\frac{(n+2) \sqrt{3}}{4} \cos \alpha_{0}+\frac{n}{4} \sin \alpha_{0} \\
+\frac{n \sqrt{3}}{4} \cos \left(\alpha_{b}+\gamma_{b}\right)-\frac{n}{4} \sin \left(\alpha_{b}+\gamma_{b}\right) \\
+\frac{(n+1) \sqrt{3}}{2} \cos \left(\alpha_{0}+\gamma\right)
\end{array}\right]
$$

c) For $\left(\gamma+\alpha_{0}-\gamma_{b}\right) \leq \alpha_{b} \prec\left(2 \pi / 3-\gamma_{b}\right)$. The limits of output voltage are give as:

$$
V_{d}=\left.\frac{3}{\pi} \frac{\overline{V_{C}}+V_{A}}{2}\right|_{(\pi / 6)+\alpha_{0}} ^{(\pi / 6)+\alpha_{b}+\gamma}
$$

$$
V_{d}=\left.\frac{3}{\pi} V_{A}\right|_{(\pi / 6)+\alpha_{b}+\gamma} ^{(\pi / 6)+\alpha_{b}+\gamma_{b}}
$$

$V_{d}=\left.\frac{3}{\pi} \overline{V_{A}}\right|_{(\pi / 6)+\alpha_{b}+\gamma_{b}} ^{(5 \pi / 6)+\alpha_{0}}$

Therefore

$$
V_{d}=\frac{V_{0}}{\sqrt{3}}\left[\begin{array}{l}
\frac{(n+2) \sqrt{3}}{4} \cos \alpha_{0}+\frac{n}{4} \sin \alpha_{0} \\
+\frac{n \sqrt{3}}{4} \cos \left(\alpha_{b}+\gamma_{b}\right)-\frac{n}{2} \sin \left(\alpha_{b}+\gamma_{b}\right) \\
+\frac{(n+1) \sqrt{3}}{4} \cos \left(\alpha_{0}+\gamma\right)+\frac{n}{4} \sin \left(\alpha_{0}+\gamma\right)
\end{array}\right]
$$

Where

$$
\begin{aligned}
& \gamma=\cos ^{-1}\left[1-\frac{\left(X_{0}+X_{b}\right) I_{d}}{V_{p h} \sqrt{6\left(1+n+n^{2} / 3\right)}}\right] \\
& \left.\gamma_{b}=\cos ^{-1}\left[\operatorname{co} \$ \pi / 6+\alpha_{b}\right)-\frac{X_{b} I_{d}}{n V_{p h} \sqrt{2}}\right]-\left(\alpha_{b}+\pi / 6\right)
\end{aligned}
$$

The overlap $\gamma$ is related to the output current $I_{d}$ (assumed constant), then

$$
\begin{aligned}
& I_{d}=\frac{\sqrt{6\left(1+n+n^{2}\right)}}{Z_{1}}\left[\cos \left(\frac{\pi}{6}+\alpha+\alpha_{0}+\theta_{2}\right) e^{-\gamma R_{t} / X_{t}}\right. \\
& \left.-\cos \left(\frac{\pi}{6}+\alpha+\alpha_{0}+\gamma+\theta_{2}\right)\right]
\end{aligned}
$$

Where

$$
\begin{array}{ll}
\theta_{2}=\tan ^{-1}\left(R_{t} / X_{t}\right), & R_{t}=2 R_{m}+R_{b} \\
X_{t}=2 X_{m}+X_{b}, & Z_{1}=\sqrt{R_{t}^{2}+X_{t}^{2}}
\end{array}
$$

Also, the overlap angle $\gamma_{b}$ is related to $I_{d}$

$$
I_{d}=\frac{\sqrt{2} n V}{Z_{2}}\left[\begin{array}{l}
\cos \left(\alpha_{b}+\alpha_{0}+\pi / 6+\theta_{3}\right) e^{-\gamma_{b} R_{b} / X_{b}} \\
-\cos \left(\alpha_{b}+\alpha_{0}+\pi / 6+\gamma_{b}+\theta_{3}\right)
\end{array}\right]
$$


Where

$Z_{2}=\sqrt{R_{b}^{2}+X_{b}^{2}} \quad$ and $\quad \theta_{3}=\tan ^{-1}\left(R_{b} / X_{b}\right)$

d) For $\left(2 \pi / 3-\gamma_{b}\right) \leq \alpha_{b} \prec(2 \pi / 3)$, in this case the limits of the output voltage are given As:

$$
\begin{aligned}
& V_{d}=\left.\frac{3}{\pi} \frac{\overline{V_{C}}+V_{A}}{2}\right|_{(\pi / 6)} ^{(\pi / 6)+\gamma} \\
& V_{d}=\left.\frac{3}{\pi} \overline{V_{A}}\right|_{(\pi / 6)+\gamma} ^{(5 \pi / 6)}
\end{aligned}
$$

Therefore

$V_{d}=\frac{V_{0}}{2}[1+\cos \gamma]$

Where $\gamma=\cos ^{-1}\left[1-\frac{X_{c} I_{d}}{\sqrt{6} V_{p h}}\right]$

\subsection{Inverter mode of operation}

For the inverter mode of operation, the bypass thyristor S2 is fired with the main thyristor S3, and the DC voltage is controlled by the angle of advance $\beta_{m}$ of device S1. Fig. 8 shows the typical voltage and current waveforms for Modified converter (Inverter). The angle at which natural commutation occurs is $\beta_{0}$ due to the difference between the main and by-pass voltages.

$\beta_{0}=\alpha_{0}=\tan ^{-1}\left[\frac{n \tan (\pi / 6)}{2+n}\right]$

The effect of $\beta_{0}$ is to increase slightly the angle of lag of the phase currents and the reactive voltampere absorption. The limits of the output voltage are given by:

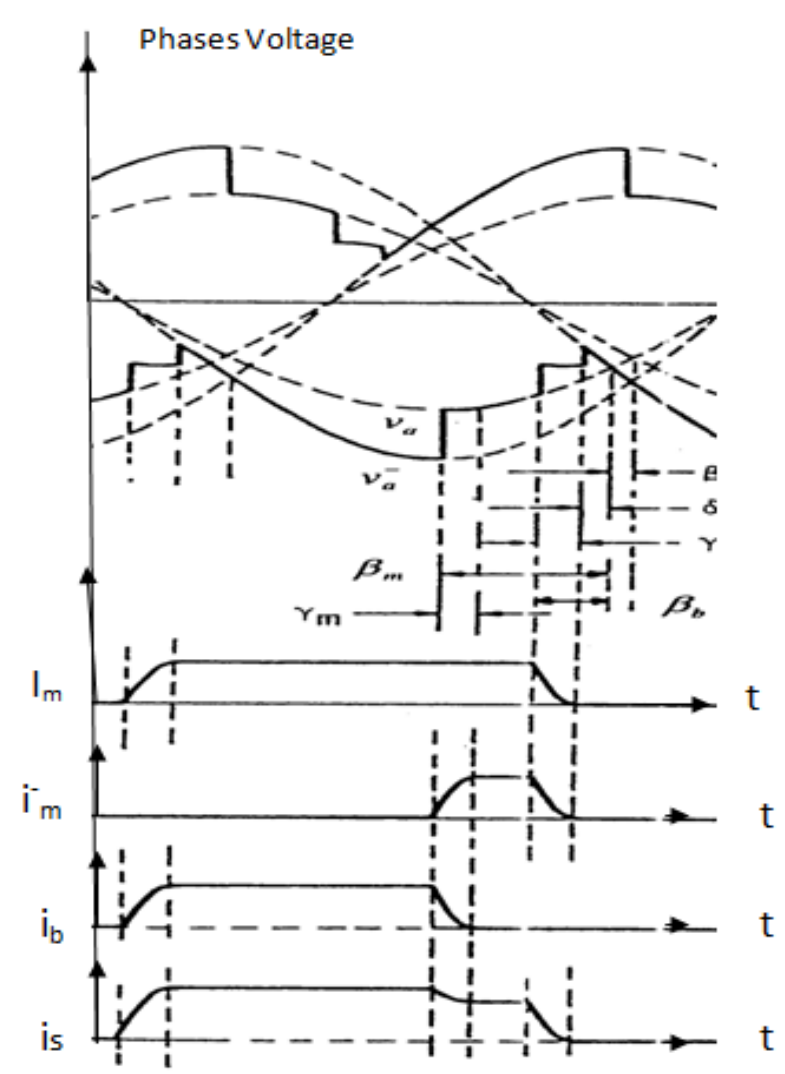

Fig.8: Typical voltage and current waveforms for Modified converter (Inverter) [19]

$$
\begin{aligned}
V_{d} & =\left.\frac{3}{\pi} \overline{V_{A}}\right|_{(7 \pi / 6)-\beta-\delta} ^{(11 \pi / 6)-\beta_{b}} \\
V_{d} & =\left.\frac{3}{\pi} V_{A}\right|_{(11 \pi / 6)-\beta_{b}} ^{(11 \pi / 6)-\beta_{b}-\delta-\gamma} \\
V_{d} & =\left.\frac{3}{\pi} \frac{V_{A}+\overline{V_{B}}}{2}\right|_{(11 \pi / 6)-\beta_{0}-\delta-\gamma} ^{(11 \pi / 6)-\delta-\beta_{0}}
\end{aligned}
$$

Therefore

$$
V_{d}=\frac{V_{0}}{\sqrt{3}}\left[\begin{array}{l}
\left.\frac{\sqrt{3} n}{2} \cos \beta_{b}-\frac{n}{2} \sin \beta_{0}+\frac{\sqrt{3}(n+2)}{4} \cos \delta+\beta_{0}\right) \\
\left.+\frac{n}{4} \sin (\delta+\beta)+\frac{(n+2) \sqrt{3}}{4} \cos \beta_{0}+\delta+\gamma\right) \\
+\frac{n}{4} \sin \left(\beta_{0}+\delta+\gamma\right)
\end{array}\right]
$$




$$
\gamma=\cos ^{-1}\left[\cos \delta-\frac{\left(X_{0}+X_{b}\right) I_{d}}{V_{p h} \sqrt{6\left(1+n+n^{2} / 3\right)}}\right]-\delta
$$

\section{Results and discussion}

A proposed configuration that uses by-pass valves connected to tapping points on the secondary side of the converter input transformer, has been investigated. Fast and continuous control of the DC voltage is possible using the proposed configuration. The DC voltage may be varied over a range of say, $\pm 25 \%$ with the new circuit feature as shown in Fig. 9.

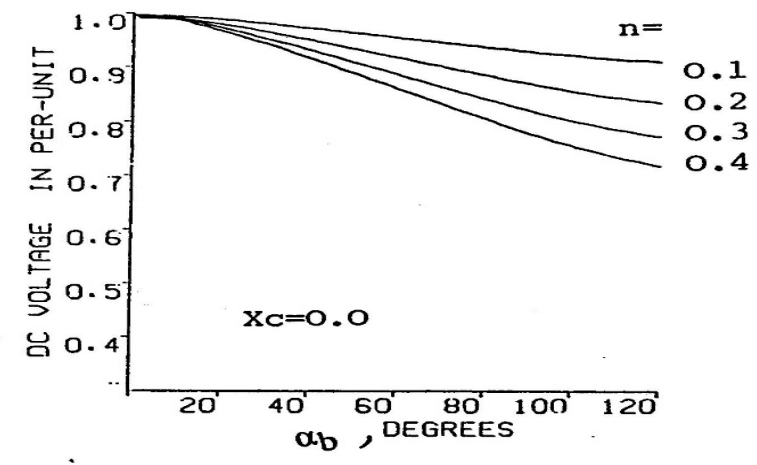

Fig.9: DC voltage for modified Converter [18], [19], $[20,[21]$

A comparison of results between the modified converter and a conventional converter indicates that there is a reduction in the VAR absorption of about $10 \%$, to give the corresponding value of DC voltage when the conventional converter works at a typical operating point as shown in Fig.10 and Fig.11. At the normal operating point, the harmonic content of the supply current also generally reduced. It can be noted from the results that, the value of the tap-section ratio (n) is equal to $0.1 \mathrm{p} . \mathrm{u}$ which is sufficient to handle small sudden changes in AC system voltage ( say $\pm 5 \%$ ), as with $\alpha$ control in a conventional converter. Alternatively with a value of (n) equal to $0.3 p . u$ it is sufficient to handle large changes of AC voltage ( say $\pm 15 \%$ ), so that a tap-changer is not necessary. Fig. 12 shows reactive volt-ampere for conventional and modified converter at different values of input reactance's $X_{C}$ against DC voltage $V_{d}$.

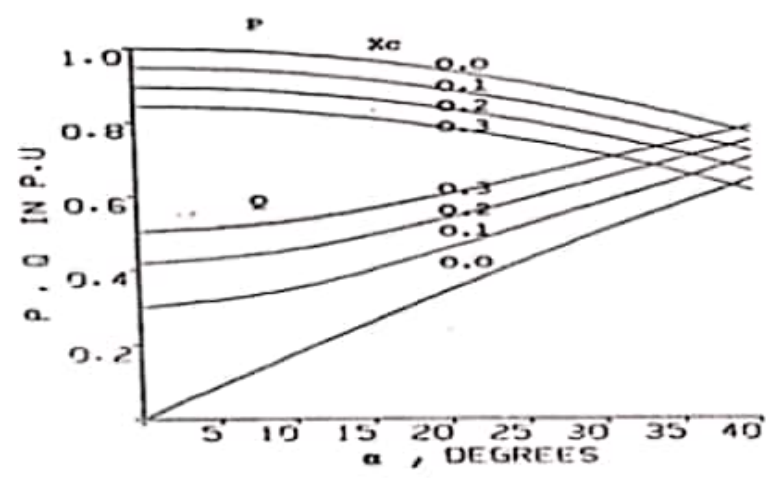

Fig.10: Active and Reactive Volt-ampere for Conventional converter [18], [19], [20, [21]

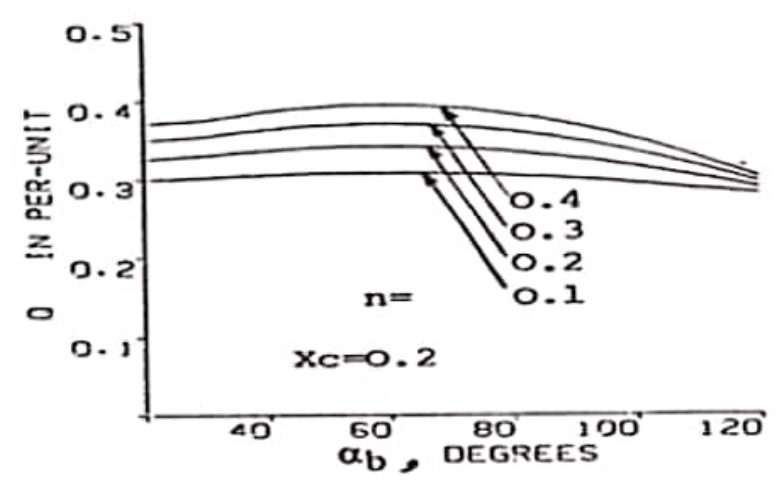

Fig.11: Reactive Volt-ampere for Modified converter [18], [19], [20, [21]

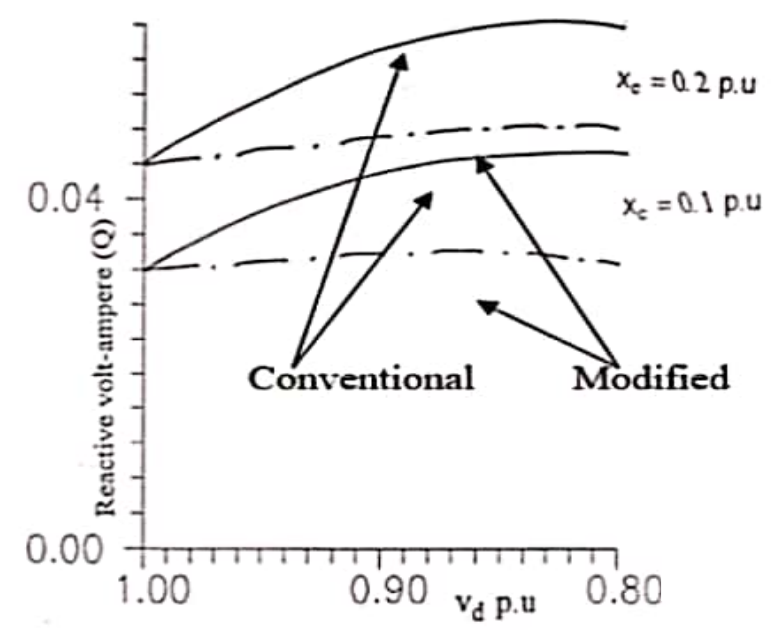

Fig.12: Reactive power for conventional and modified converters [18], [19], [20, [21]

Commutation reactance was considered in the analysis of the converter. It was 
found that as the commutation reactance $x_{C}$ increases the output voltage and the magnitude of the supply current harmonics decrease while the reactive volt-ampere absorption is increased ( as expected).

With the modified converter control a starconnected primary, there are significant triples harmonics, due to additional tap-section turns in the secondary side which is energized for a part of the main thyristor conducting period. This is a disadvantage of this form of control and a delta connected tertiary is then required with a star/star connected transformer to give triples harmonic ampere-turn balance in the converter transformer core. Fig. 13 shows the computed results for the harmonic content of the AC phase current for modified bridge operating at a typical firing angle of $17^{\circ}$ the harmonic content of the supply current is generally reduced with by-pass thyristor control as shown in Fig.14.

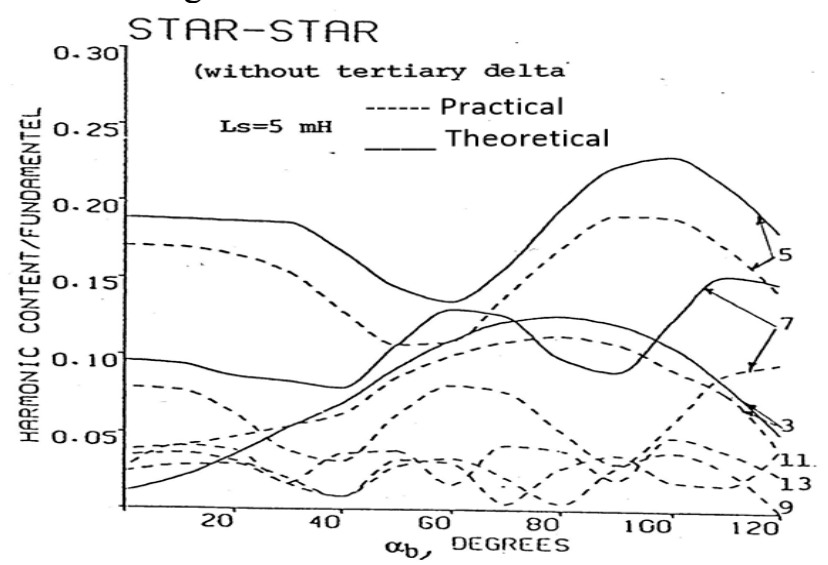

Fig.13: Harmonics for modified converter

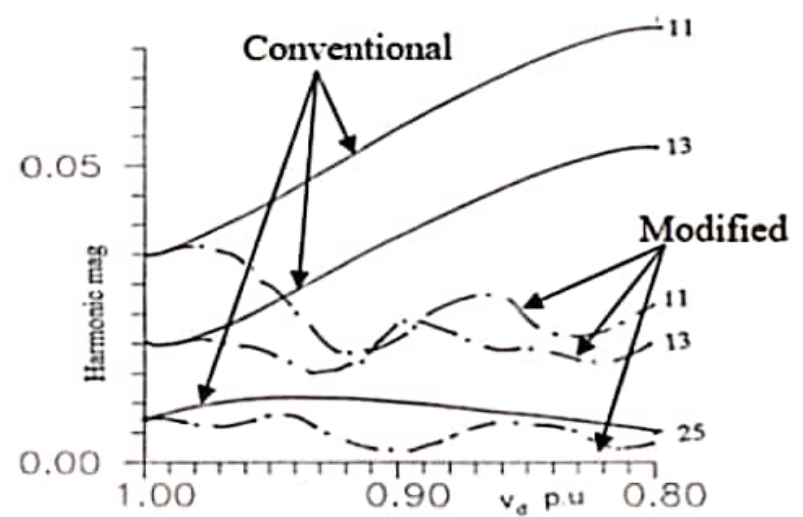

Fig.14: harmonics for Conventional and Modified converters

The possible advantages of the modified converter may be summarized briefly as follows:
1. Reduction of characteristic harmonics

2. Reduction of reactive volt-ampere absorption

3. Fast and continuous control of DC voltage are possible with good operational characteristics

4. Feasibility of tap-changer elimination on the converter transformer.

Further work is required to replace the conventional thyristors by high power isolated gate bipolar transistors ( IGBT) which have been developed in recent years. The self turn-off capability and high $\mathrm{di} / \mathrm{dt}$ rating of the IGBT provide advantages over conventional circuit commutated thyristors.

\section{Conclusions}

The computed and experimental results were in good agreement and showed the general characteristics obtained using by-pass valves control. A voltage range of about , $\pm 25 \%$ was possible by varying $\alpha_{b}$ over $120^{\circ}$ with the model bridge, where the tap-section ratio (n) is 0.4 p.u.. In the modified converter, there is a reduction in VAR absorption of about $10 \%$, to give the corresponding value of DC voltage when the conventional converter works at a typical operating angle, in the region of $12^{\circ}$ and $18^{\circ}$.

The results were taken at different values of series inductance $L_{S}$.It was clear that as $L_{S}$ increases the DC voltage and the magnitude of $\mathrm{AC}$ current harmonics reduces and the VAR increases. With the modified converter control and a star-connected primary, there are significant triplen harmonics. This is a disadvantage of this form of control. Hence a delta-connected or tertiary winding is necessary to give triplen-harmonic ampere -turn balance in the converter transformer cores.

\section{Nomenclature}

$V_{d}=\mathrm{DC}$ voltage

$V_{p h}=$ RMS value of phase voltage

$V_{\text {th }}=$ on-state device voltage

$I_{d}=$ DC current in HVDC line

$i_{m}=$ instantaneous value of main thyristor current

$i_{p}=$ instantaneous value of by-pass thyristor current $n=$ transformer tap-section turns (p.u) 
$X_{C}=$ main thyristor commutation reactance

$X_{b}=$ by-pass thyristor commutation reactance

$L_{S}=$ inserted inductance with primary side of transformer

$\alpha=$ delay angle of main thyristor

$\alpha_{0}=$ delay angle due to unequal thyristor voltages

$\alpha_{b}=$ delay angle of by-pass thyristor

$\gamma=$ commutation angle due to main thyristor ( S1)

$\gamma_{b}=$ commutation angle due to by-pass thyristor (

$\mathrm{S} 2)$

$\beta_{0}=$ angle of advance due to unequal thyristor voltages

$\beta_{b}=$ angle of advance of by-pass thyristor ( S2) in inverter operation

$\beta_{m}=$ angle of advance of main thyristor (S1)

$\delta=$ safety angle in inverter operation

\section{References}

[1] N. H. Malik and S. E. Haque, Harmonics analysis of three-phase AC voltage controllers, IEEE, IAS annual meeting, Denver, CO, USA, Vol.2, 1986, 1078-1085.

[2] R. Ramanathan, Harmonic analysis of a three-phase bridge converter with commutation overlap, IEEE, IAS Annual meeting, PT.II, Cincinnati, OH,USA, 1980, 816-820.

[3] M. H. Rashid and A. I. Maswood, Harmonics generated by AC-DC converter into the power supply, $28^{\text {th }}$ Midwest sympoium on circuit and system, Louisville, ky, USA, 1985, 337340.

[4] H. D. Al-Majali, "Abnormal Harmonics Generated by Modified HVDC Converters" Electric Power Components and Systems (Taylor \& Francis). Vol.35, No.6, 2006, PP 639 654.

[5] A. G. Phadke and J. H. Harlow, Generation of abnormal Harmonics in high voltage AC-DC power systems, IEEE. Transactions on power Apparatus and systems, Vol. PAS-87, No.3,1968, 873-883.

[6] J. Reeve and P. C. Krishanayya, Unusual current harmonics arising from high voltage DC transmission, IEEE Transactions on power Apparatus and systems, Vol.PAS-87, No-3, 1968, 883893.

[7] T. Subbarao and J. Reeve, Harmonics caused by imbalanced transformer impedance and imperfect twelve-pulse operation in HVDC conversion, IEEE Transaction on power Apparatus and systems, Vol.PAS-95, No.5, 1976, 1732-1735.

[8] Y. Wang and L. Pierrat, probabilistic modeling of current harmonics produced by a $\mathrm{AC} / \mathrm{DC}$ converter under voltage unbalance. IEEE Transactions on power Delivery, Vol.8, No.4, 1993, 2060-2066.

[9] K. Olejniczak and G. T. Heydt, Basic mechanisms of generation and flow of harmonic signals in balanced and unbalanced three-phase power systems, IEEE Transactions on power Delivery, Vol.4, 1989, 2162-2169.

[10] X. Wilsum, J. E. Drakos , Y. Mansour and A. Chang, Athree-phase converter model for harmonic analysis of HVDC systems, IEEE. Transaction on Power Delivery, Vol.9, No.3, 1994, 1724-1731.

[11] Xiaojie Shi, Zhiqiang Wang and Bo Liu, Characteristic Investigation and Control of a Modular Multilevel Converter-Based HVDC System Under Single-Line-to-Ground Fault Conditions, Vol.30, No.1, 2015, 408421.

[12] H. D. Al-Majali, "Voltage Control of Series - Connected Modified HVDC Bridge Using GTO Thyristor by-pass Valves", Electric Power Systems Research (Elsevier), Vol. 49, No.2, 1999, PP. 79-86.

[13] H. D. Al-Majali and S. Al-Dhalaan, "Transient of Modified HVDC Converter", Electric Power Systems Research (Elsevier), Vol.77, No. 10, 2007, PP. 1329 - 1336.

[14] H. D. Al-Majali, "Voltage Control of Modified Series - Connected HVDC Bridges", Electric Power Systems Research (Elsevier), Vol.43, 1997, PP. $37-44$.

[15] H. D. Al-Majali and S. Al-Dhalaan, 
" A Snubber Configuration for Modified Bridge Converter", Electric Power Systems Research (Elsevier), Vol.34, No. 11, 2006, PP. $1177-1190$.

[16] M. W. Alzahlan, K.M. Alawasa and H.D. Al-Majali, "Performance Evaluation of Different Optimal-tund Current Controllers for Voltage-Source Converter Connected to a Weak AC Grid", IEEE Jordan International Joint Conference on Electrical Engineering and Information Technology, JEEIT 2019- Proceeding

[17] S. Al-Dhalaan, H. D. Al-Majali and D. O'Kelly, "HVDC Converter Using Self - Commutated Devices", IEEE Transactions on Power Electronics, Vol. 13, No.6, 1998, PP. $1164-1173$.

[18] H. D. Al-Majali and D. O'Kelly, "Control of an HVDC Converter Using GTO Thyristor By-Pass Valves", $26^{\text {th }}$ UPEC (, Brighton Polytechnic, U.K, 1991, PP 36-39.

[19] H. D. Al-Majali and D. O'Kelly, "Control of an HVDC Converter Using By-Pass Valves", 25 ${ }^{\text {th }}$ UPEC, Robert Gordon's Institute of Technology, Aberdeen, U.K, 1990. PP 652-656.

[20] H. D. Al-Majali and S. Al-Dhalaan, " Control of Series HVDC Bridges with Different Firing Angles" WSEAS Transaction on Power Systems, Vol.14, 2014.PP. 418 -427.

[21] H. D. Al-Majali and B. H. AlMajali, "Fast and Continuous Control of a Modified HVDC Converter", WSEAS Transaction on Systems and Control, Vol.14, 2019, PP. 326-332.

Creative Commons Attribution License 4.0 (Attribution 4.0 International, CC BY 4.0) This article is published under the terms of the Creative Commons Attribution License 4.0 https://creativecommons.org/licenses/by/4.0/d eed.en_US 